\title{
Scheimpflug Imaging in Unilateral Acute Pupillary Block Glaucoma in a Weill-Marchesani Syndrome in an Adult Female
}

Manish Chaudhary, Jagat Ram, Nishant Gupta, Neelam Verma

\begin{abstract}
We report an interesting case of Weill-Marchesani syndrome presenting as unilateral acute pupillary block glaucoma after dislocation of crystalline lens into anterior chamber in a middleaged woman. Scheimpflug imaging demonstrated accurately the dimensions of spherophakic crystalline lens and its corneal lenticular touch. Glaucoma resolved completely after lensectomy and anterior vitrectomy and she achieved best corrected visual acuity of $20 / 30$
\end{abstract}

Keywords: Brachydactyly, Pupillary block glaucoma, Scheimpflug image, Spherophakia, Weill-Marchesani syndrome.

How to cite this article: Chaudhary M, Ram J, Gupta N, Verma N. Scheimpflug Imaging in Unilateral Acute Pupillary Block Glaucoma in a Weill-Marchesani Syndrome in an Adult Female. J Postgrad Med Edu Res 2012;46(3):152-154.

Source of support: Nil

Conflict of interest: None declared

\section{INTRODUCTION}

The syndrome of Weill-Marchesani (WMS) is a rare hereditary affection, retrieved for the first time by Weill in $1932,{ }^{1}$ then described in 1936 by Marchesani. ${ }^{2}$ Alternatively, it has been named spherophakiabrachymorphia syndrome, or congenital mesodermal dysmorphodystrophy. Diagnostic criteria of WMS includes: (1) Short stature, (2) brachydactyly, (3) microspherophakia and/or ectopia lentis. ${ }^{3}$ The principal complication is the secondary glaucoma that is frequent in the absence of treatment. Spherophakia is an uncommon condition in which the small, spherical lens may leads to pupillary block and secondary angle closure glaucoma. ${ }^{4,5}$ We present a case of WMS presenting as unilateral acute pupillary block glaucoma in a middle-aged woman documented with Scheimpflug image.

\section{CASE REPORT}

A 40-year-old Sikh woman presented with acute pain and decreased vision in right eye since 5 days. She had a history of treatment with oral acetazolamide, $4 \%$ pilocarpine drops in right eye for last 5 days. There was no light perception in the left eye for the last 13 years following similar complaint and history of lensectomy in left eye 6 years back following which symptom got relieved. At presentation, the right eye had a visual acuity of counting finger close to face (CFCF) and no light perception in left eye; intraocular pressure (IOP) was 50 and $34 \mathrm{~mm} \mathrm{Hg}$ in the right and left eye respectively. There was diffuse epithelial corneal edema. Spherical dislocated lens was present in the anterior chamber touching corneal endothelium in the right eye (Fig. 1A). The left eye had steel suture at the superior limbus, vascularized leucomatous corneal opacity inferiorly, few epithelial bullae and stromal edema. There was aphakia with anterior capsular opacification, retained lens matter. Retinoscopy was not possible owing to the poor fundal glow due to corneal edema in right eye and vascularized corneal opacity in left eye. The axial length was 24.58 and $26.19 \mathrm{~mm}$ in the right and left eye respectively. B-scan ultrasonography showed normal posterior segments in both eyes. The optic disk and posterior segment was normal in right eye and advanced glaucomatous cupping was present in left eye.

Scheimpflug image obtained using Oculus Pentacam of right eye showed spherical lens touching corneal endothelium as well as subluxated from patellar fossa. The lens thickness was 5,000 microns and distance between posterior lens surface and patellar fossa was1,470 microns (Fig. 1B). Scheimpflug imaging showed corneal thickness varying between 653 and 865 micron. Right eye keratometry was $45.8 \mathrm{D}$ at $90^{\circ}$ and $50 \mathrm{D}$ at $180^{\circ}$.

\section{Systemic Findings}

Patient's height was $142 \mathrm{~cm}(150 \pm 12 \mathrm{~cm})$ and weight $60 \mathrm{~kg}$. Electrocardiogram was normal. There was brachydactyly (Fig. 1C) and no joint hypermobility.

The patient was given intravenous injection mannitol $20 \%, 350 \mathrm{ml}$ stat followed by systemic acetazolamide $250 \mathrm{mg}$ four times a day, topical timolol maleate $0.5 \%$ twicea-day and brimonidine $0.15 \%$ thrice-a-day. The IOP reduced to 28 and $20 \mathrm{~mm} \mathrm{Hg}$ in the right and left eye respectively after treatment.

Patient underwent right eye lensectomy with anterior vitrectomy with peripheral iridectomy from limbal route with vitreous cutter and no IOL implanted.

At first postoperative day, the best corrected visual acuity (BCVA) in right eye was 20/40 and IOP was $24 \mathrm{~mm} \mathrm{Hg}$. 
There was mild corneal edema, few Descemet's folds. Pupil was mid dilated and there was a peripheral iridectomy at 9 o' clock (Fig. 1D), the optic disk was normal with cupdisk ratio of 0.2 and healthy neuroretinal rim. Twelve weeks later BCVA of right eye was 20/30 [+2.5 DS with rigid gas permeable (RGP) contact lens and base curve of $7.2 \mathrm{~mm}$ and diameter $9 \mathrm{~mm}$ ] and IOP was $17 \mathrm{~mm} \mathrm{Hg}$ with topical timolol maleate $0.5 \%$ twice-a-day with CD ratio of 0.2 and healthy optic disk. Left eye IOP was $24 \mathrm{~mm} \mathrm{Hg}$ on topical timolol maleate $0.5 \%$ twice-a-day and brimonidine $0.15 \%$ twice-a-day and patient was symptom free in the left eye. Postoperative gonioscopy showed the open angles in right eye and left gonioscopy not possible due corneal opacity.

\section{DISCUSSION}

This is the first reported case of microspherophakia presenting as unilateral acute pupillary block glaucoma in an adult female and Scheimpflug image demonstrated accurately the dimensions of spherophakic crystalline lens and its corneal lenticular touch.
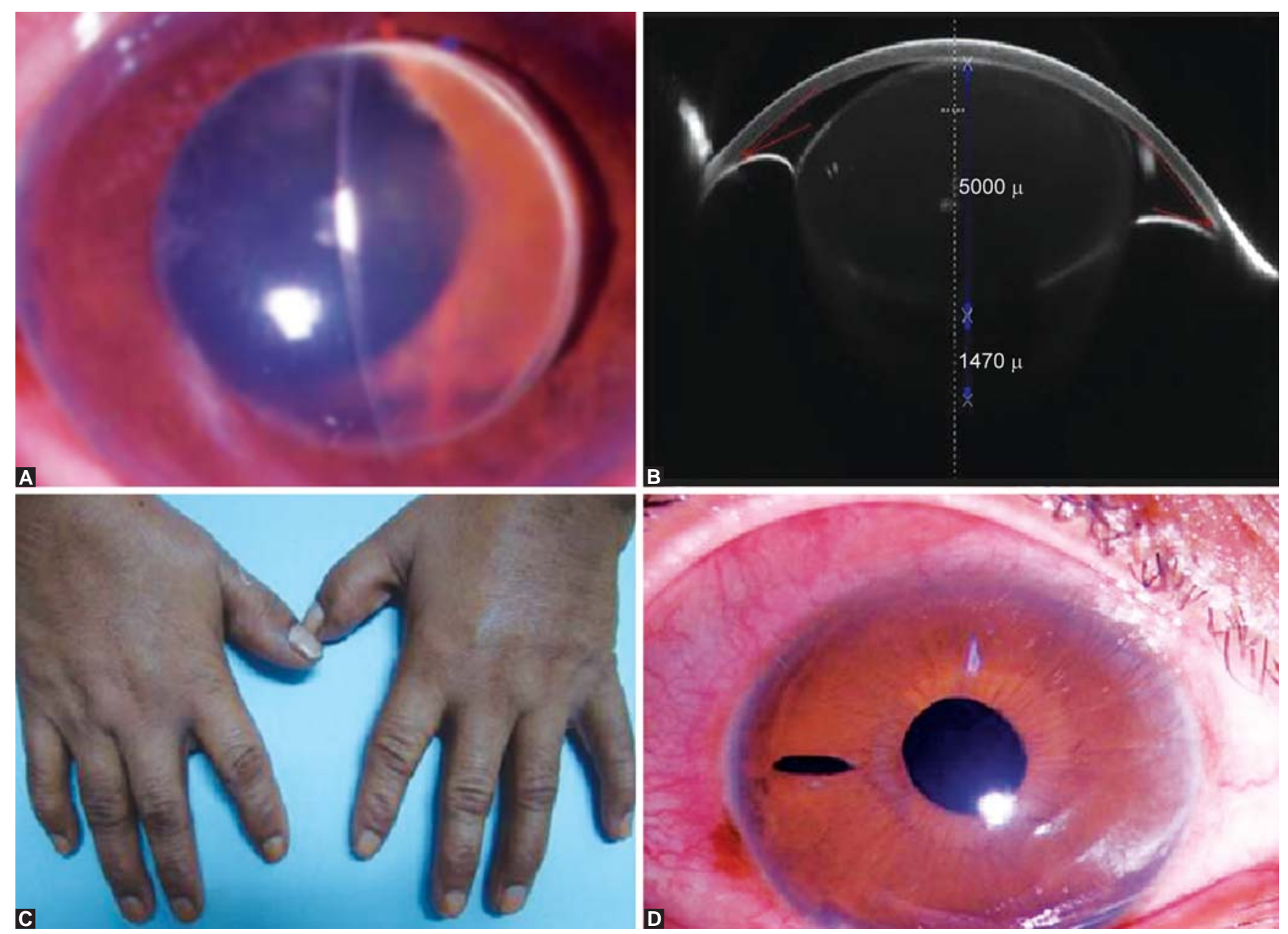

Figs 1A to D: (A) Right eye with anteriorly dislocated crystalline lens touching endothelium; (B) Scheimpflug image of right eye showing crystalline dislocated lens into anterior chamber touching corneal endothelium; (C) brachydactyly; (D) twelve weeks postoperative right eye of the patient with clear cornea. There is aphakia with peripheral iridectomy
Microspherophakia is usually associated with systemic disorders, such as WMS, homocystinemia, Marfan's syndrome, Alport's syndrome and Klinefelter's syndrome. ${ }^{6-}$ 9 Our patient had features suggestive of WMS with bracydactyly, short stature and spherophakia with acute pupillary block glaucoma. Glaucoma in spherophakia can result from several mechanisms: Pupillary block by the spherical lens, irritation of the ciliary body by the dislocated lens, ${ }^{10}$ or by complete luxation of the lens into the anterior chamber. Unrelieved pupillary block may lead to peripheral anterior synechiae (PAS) formation and irreversible trabecular damage. Chronic pupillary block without complete angle closure may lead to crowding of the trabeculae by the spherophakic lens. ${ }^{8}$ Our patient presented with unilateral acute pupillary block glaucoma, which was worsened by miotics and relieved to some extent by cycloplegic treatment. Our patient had right eye acute glaucoma secondary to pupillary block which was relieved after lensectomy and anterior vitrectomy. The IOP in our patient remained controlled with timolol maleate medication postoperatively and patient achieved good visual outcome. 


\section{REFERENCES}

1. Weill G. Ectopie of the crystalline and general malformations. Ann Oculist 1932;169:21-44.

2. Marchesani O. Brachydactylie und angeborene kungellinse Al systemerk-rankung. Klin Monatsbl Augenheilkd 1939;103: 392-406.

3. Faivre L, Dollfus H, Lyonnet S, et al. Clinical homogeneity and genetic heterogeneity in Weill-Marchesani syndrome. Am J Med Genet A 2003;123:204-07.

4. Pecora JL. Malignant glaucoma worsened by miotics in a postoperative angle-closure glaucoma patient. Ann Ophthalmol 1979;11:1412-14.

5. Merritt JC. Malignant glaucoma induced by miotics postoperatively in open-angle glaucoma. Arch Ophthalmol 1977;95: 1988-89.

6. Macken PL, Pavlin CJ, Tuli R, Trope GE. Ultrasound biomicroscopic features of spherophakia. Aust N Z J Ophthalmol 1995;23:217-20.

7. Nelson LB, Maumenee IH. Ectopia lentis. Surv Ophthalmol 1982;27:143-60.

8. Johnson GJ, Bosanquet RC. Spherophakia in a New-Foundland family: 8 years experience. Can J Ophthalmol 1983;18: 159-64.

9. Johnson VP, Grayson M, Christian JC. Dominant microspherophakia. Arch Ophthalmol 1971;85:534-42.
10. Probert LA. Spherophakia with brachydactyly. Comparison with Marfan’s syndrome. Am J Ophthalmol 1953;36:1571-74.

\section{ABOUT THE AUTHORS}

\section{Manish Chaudhary}

Senior Resident, Advanced Eye Centre, Postgraduate Institute of Medical Education and Research, Chandigarh, India

\section{Jagat Ram (Corresponding Author)}

Professor, Advanced Eye Centre, Postgraduate Institute of Medical Education and Research, Chandigarh-160012, India Phone: +91-172-2711419, Fax: +91-172-2747837, 91-172-2744401 e-mail: drjagatram@yahoo.com

\section{Nishant Gupta}

Senior Resident, Advanced Eye Centre, Postgraduate Institute of Medical Education and Research, Chandigarh, India

\section{Neelam Verma}

Senior Resident, Advanced Eye Centre, Postgraduate Institute of Medical Education and Research, Chandigarh, India 